\title{
THE ALTRUISTIC PERSONALITY AND THE SELF-REPORT ALTRUISM SCALE*
}

\author{
J. Philippe Rushton, $\uparrow$ Roland D. Chrisjohn and G. Cynthia Fekren \\ Department of Psychology, Faculty of Social Science, \\ The University of Western Ontario, Canada
}

(Received 16 March 1981; in revised form 26 March 1981)

\begin{abstract}
Summary-This paper is divided into two parts. In the first, the rank order stability of individual differences in altruism across situations is examined and it is found that substantial consistency occurs when due regard is given to the principle of aggregation. In the second, a self-report altruism scale, on which respondents rate the frequency with which they have engaged in some 20 specific behaviors, is found to predict such criteria as peer-ratings of altruism, completing an organ-donor card, and paper-and-pencil measures of prosocial orientation. These data suggest there is a broad-based trait of altruism.
\end{abstract}

\section{INTRODUCTION}

In this paper we will attempt to demonstrate that there is more consistency to altruistic behavior across situations than might often be supposed, i.e., that there is a trait of altruism-indeed one sufficiently broad to warrant the concept of 'the altruistic personality.' First, we review the literature on the consistency of altruistic behavior, and second we demonstrate that individual differences in altruistic behavior can be measured directly by a self-report altruism scale.

\section{THE CONSISTENCY OF ALTRUISTIC BEHAVIOR}

If a survey were to be taken of researchers in the field of altruism as to whether they believed there was such an entity as 'the altruistic personality' the majority would answer with a resounding 'no.' There are very few, if any, programs of research in operation on consistent patterns of individual differences in altruistic behavior, although just about every other conceivable research approach has been used (see e.g. Rushton and Sorrentino, 1981). No, researchers do not study the altruistic personality for the fairly compelling reason that they don't believe there is such a thing. For example, Krebs wrote

"As Hartshorne and May showed a half century ago, just about everyone will help in some situations; just about nobody will help in other contexts; and the same people who help in some situations will not help in others."

and

"There is little basis fo. resisting Gergen et al.'s characterization of personality research on altruism as a "quagmire of evanescent relations among variables, conflicting findings, and low order correlation coefficients' (Gergen et al., 1972, p. 113)."

(Krebs, 1978, p. 142)

Krebs is certainly not alone in his view. For example, Latané's and Darley's now classic monograph concluded:

"There are ... reasons why personality should be rather unimportant in determining people's reactions to the emergency. For one thing, the situational forces affecting a person's decision are so strong...

* Portions of this paper were presented at the International Conference on Prosocial Behavior, Warsaw, Poland, in June 1980, entitled "The altruistic personality", and the 22nd International Congress of Psychology, Leipzig, German Democratic Republic, in July 1980, entitled "The altruistic personality and childhood antecedents."

† Present address: Department of Psychology, University of Western Ontario, London, Ontario, Canada N6A 5C2: and to whom all reprint requests should be addressed. 
A second reason why personality differences may not lead to differences in overt behavior in an emergency is that they may operate in opposing ways at different stages of the intervention process."

(Latané and Darley, 1970, p. 115)

In short, many investigators have a pessimistic view of the likelihood of finding a trait of altruism. One reason for this is that they believe in the 'specificity' view of behavior, based first on the finding that the typical coefficient of consistency across situations is +0.30 , and second on the belief that this coefficient is too low to make the concept of a trait (altruistic or otherwise) very useful (Mischel, 1968).

For several decades there have been two opposing viewpoints on the question of whether human behavior is generally consistent in different situations. Known as the 'specificity versus generality' controversy, the question has loomed particularly large in the area of personality and moral behavior. The classic study of this problem was the enormous Character Education Enquiry carried out by Hartshorne and May in the 1920s and published from 1928 to 1930 in three books: Studies in Deceit, Studies in Service and Self-Control and Studies in the Organization of Character. This was an extremely influential study that, as Eysenck (1977) and Rushton (1980) have pointed out, has been seriously misinterpreted. Let us briefly consider it in a little detail.

These investigators gave 11,000 elementary and high-school students some 33 different behavioral tests of their altruism (referred to as the 'service' tests), self-control and honesty in home, classroom, church, play and athletic contexts. At the same time extensive ratings of the children's reputations with their teachers and their classmates were taken in all these areas. By intercorrelating the children's scores on all these tests it was possible to discover whether the children's behavior was specific to situations or generalizable across them. If the children's behavior is specific to situations then the correlations across situations should be extremely low or even nonexistent. If the children's behavior is generalizable across situations then the correlations should be substantial. We thus have a crucial test of the generality hypothesis.

What were the results from this extremely large and intensive study? First, let us consider their measures of altruism. The behavioral indices intercorrelated a low average of +0.23 on the average, thus suggesting support for the specificity viewpoint. If the five measures were combined into a battery, however, they correlated a much higher +0.61 with the measures of the child's altruistic reputation among his or her teachers and classmates. Hartshorne et al. (1929) wrote, in this regard:

"The correlation between the total service score and the total reputation score is $0.61 \ldots$ Although this seems low, it should be borne in mind that the correlations between test scores and ratings for intelligence seldom run higher than 0.50." (Vol, 2, p. 107, italics added)

On the "Guess Who" test of reputation (e.g. "Guess Who is kind to younger children?") the teachers' perceptions of the students' altruism agreed extremely highly with that of the students' peers $(r=0.81$, Hartshorne et al., 1929, Vol. 2, p. 91). Taken together these latter results indicate a considerable degree of generality and consistency in altruistic behavior.

Virtually identical results as the above were found for the measures of honesty and self-control. Any one behavioral test correlated, on average, only a modest +0.20 with any one other behavioral test. If, however, the measures were combined into more reliable batteries, then much higher relationships were found with either teachers' ratings of the children or with any single measure taken alone. Typically these correlations were on the fairly high order of +0.50 and +0.60 . (See, for example, Vol. 1, Book 2, p. 130 , Table 97; Vol. 2, Book 1, p. 104, Table 20; Vol. 2, Book 2, pp. 351-352.)

Hartshorne and May (1928-30), however, focused overwhelmingly on the smaller correlations of +0.20 and +0.30 which led them to conclude in favor of the doctrine of specificity. For example, they state:

"Neither deceit nor its opposite, "honesty" are unified character traits, but rather specific functions of life situations. Most children will deceive in certain situations and not in others. Lying, cheating, and stealing as measured by the test situations used in these studies are only very loosely related."

(Hartshorne and May, 1928, p. 411) 
Their conclusions, and their data, have often been referred to in defending the specificity viewpoint. For example, Mischel (1968), in a highly influential review, extolled again the notion of specificity in behavior pointing out that the average correlation between two behavioral instances of a 'trait' is +0.20 to +0.30 . Persons, therefore, are said to exhibit 'discriminative facility' between situations.

This specificity doctrine has provided a service by emphasizing that contexts are important, and that people learn different ways of dealing with different situations. Unfortunately, some have interpreted this as meaning that consistency does not exist. This however is quite wrong. First, the +0.30 correlation is a replicable finding and indicative of at least some consistency in altruistic behavior. Second, by focusing on correlations of +0.20 and +0.30 between any two measures, a very misleading impression can be created. A more accurate representation is obtained by examining the predictability achieved from sampling a number of behavioral exemplars. Numerous exemplars are more reliable and hence better predictors, a point often made in the past (e.g., Spearman, 1910; Eysenck, 1939), but worth repeating today. This greater predictability occurs because there is always a fair amount of randomness in any one measure. By combining and summing over situations the randomness (called 'error variance') tends to average out, leaving a clearer view of what the person's true behavior is like. These expectations are made explicit in psychometric theory where, for example, in personality and educational testing, the more items there are on a test, the higher the reliability.

Imagine how inappropriate it would be for professors to assess the knowledge of the students in their courses on the basis of one or two multiple-choice items. The intercorrelations of such items is typically around +0.20 or lower. By employing a larger number of items, one obtains a far more reliable (and fairer) assessment. This also is true in measuring personality, including individual differences in altruism and, as we have seen, combining individual tasks in the Hartshorne and May (1928-30) studies led to substantial predictability. Correlations of +0.50 and +0.60 allow for the accounting of $25-36 \%$ of the variance in a set of scores.

Not only did total scores within the battery of altruism tests and measures yield evidence of consistency, but so too did measures of self-control, persistence, honesty and moral knowledge. There is, indeed, evidence for a pervasive general factor of moral character (see, e.g., Hartshorne et al., 1930, p. 230, Table 32). One of the first to note this was Maller (1934), an author of the second volume of the character education inquiry (Hartshorne et al., 1929). He dissented from the conclusion that there exists little commonality across moral behaviors. Using Spearman's tetrad difference technique, Maller $(1934$, p. 100) demonstrated a common factor throughout the intercorrelations of the character tests of honesty, altruism, self-control and persistence. Subsequently, Burton (1963), in a reanalysis of the original Hartshorne and May data, found a large general factor that accounted for between 35 and $40 \%$ of the common variance.

Since the pioneering work of Hartshorne and May (1928-30) many other studies have also provided data that speak directly to the specificity versus generality of altruism question. As has been reviewed elsewhere (Rushton, 1976, 1980) the typical correlation between any two behavioral indices is about +0.30 . Combining measures on the other hand, typically leads to greater predictability. For example, Dlugokinski and Firestone (1973) took four measures from 164 children aged 10-13: a pencil-and-paper measure of the relative importance of altruistic as opposed to selfish values; judgments from their classmates as to how considerate or selfish they were viewed to be; and a behavioral measure concerned with donating money to a charity. The six possible correlations were all positive and ranged from +0.19 to +0.38 . Further, multiple correlations of any three variables as predictors of the fourth ranged from +0.42 to +0.51 . In a later paper, Dlugokinski and Firestone (1974) replicated these relationships. Still other studies have examined the relations among children's naturally occurring altruism. For example, in an extensive investigation of children's free play behavior in a natural setting, Strayer et al. (1979) studied 26 children over a 30-hour period. These authors found relationships of 
+0.50 and +0.60 between such measures of altruism as donating and sharing objects, cooperation and helping.

The foregoing review indicates there is a trait of altruism. That is, some people are consistently more generous, helping and kind than others. Furthermore, such people are readily perceived as more altruistic, as is demonstrated by several studies showing positive relationships between behavioral altruism and peers' and teachers' ratings of how altruistic a person seems (Dlugokinski and Firestone, 1973, 1974; Hartshorne et al., 1929; Krebs and Sturrup, 1974; Rushton and Wheelwright, 1980; Rutherford and Mussen, 1968). Indeed there are several studies that have shown that individual differences in paper-and-pencil measures of such constructs as empathy, moral reasoning, and social responsibility also predict situationally measured altruism (see Rushton, 1980, for a review). We shall provide additional evidence and discussion of this shortly.

This leads us directly to the second half of this paper. If there are consistent patterns to the individual differences in altruistic behavior, then it should be possible to demonstrate this by measuring them directly through self-report questionnaires, as has been done successfully, for example, with individual differences in delinquency (e.g. Rushton and Chrisjohn, 1981). We report three investigations to support this hypothesis.

\section{THE SELF-REPORT ALTRUISM SCALE}

The Self-Report Altruism (SRA) Scale has an easy-to-administer, self-report format and consists of the 20 items shown in Table 1. Respondents are instructed to rate the frequency with which they have engaged in the altruistic behaviors using the categories 'Never', 'Once', 'More Than Once. 'Often' and 'Very Often'.

Initial analyses of data collected from two separate samples of students at the University of Western Ontario, demonstrated the SRA-scale to be psychometrically stable. The two samples yielded comparable means and standard deviations and high internal consistency (see Table 2). Furthermore, the discriminant validity of the scale was found to be good. This was assessed by examination of the correlations between it and an omnibus personality inventory measuring 20 different personality traits (Jackson, 1974). Of particular note was the correlation between the SRA-scale and a measure of social desirability $(r=0.05)$ suggesting that the SRA-scale is not merely measuring the tendency to answer in a socially desirable fashion. Several additional studies were carried out to examine the predictive validity of the SRA-scale.

\section{Study 1: peer ratings}

If the SRA-scale is validly measuring altruism, then scores on the SRA-scale should correlate with peer ratings of altruism. To examine this, 118 undergraduates at The University of Western Ontario initially filled out the SRA-scale during class time. Subsequently they were given eight peer rating forms and eight prestamped and addressed envelopes and were asked to give these forms to eight people who knew them well. Raters were to be asked to complete the forms anonymously and mail them back to the authors.

The peer rating forms were divided into two sections. One section asked the judges to assess how frequently the target subject engaged in the 20 different behaviors comprising the items of the SRA-scale. Another section asked for four global ratings of the target person's altruism - that is, how caring, how helpful, how considerate of others' feelings and how willing to make a sacrifice the individual was. Each of these ratings was to be made on a 7 -point scale.

There were 968 peer rating forms distributed to the 118 subjects who initially completed the SRA-scale in class. Approximately $45 \%$ of the peer rating forms were returned $(N=416)$ and 88 subjects ( $75 \%$ of the subjects in the original sample) had one or more raters. The mean and standard deviation for this third sample were similar to those in the two earlier samples and the internal consistency of the SRA-scale was once again found to be high (see Table 2).

A peer rating score on the 20 item scale was found by summing across the 20 items for 
Table 1. The Self-Report Altruism Scale Instructions: Tick the category on the right that conforms to the frequency with which you have carried out the following acts.

\begin{tabular}{|c|c|c|c|c|c|}
\hline & Never & Once & $\begin{array}{l}\text { More } \\
\text { than } \\
\text { once }\end{array}$ & Often & $\begin{array}{l}\text { Very } \\
\text { often }\end{array}$ \\
\hline 1. I have helped push a stranger's car out of the snow & & & & & \\
\hline 2. I have given directions to a stranger. & & & & & \\
\hline 3. I have made change for a stranger. & & & & & \\
\hline 4. I have given money to a charity. & & & & & \\
\hline $\begin{array}{l}\text { 5. I have given money to a stranger who needed it } \\
\text { (or asked me for it). }\end{array}$ & & & & & \\
\hline 6. I have donated goods or clothes to a charity. & & & & & \\
\hline 7. I have done volunteer work for a charity. & & & & & \\
\hline 8. I have donated blood. & & & & & \\
\hline $\begin{array}{l}\text { 9. I have helped carry a stranger's belongings } \\
\text { (books, parcels, etc.). }\end{array}$ & & & & & \\
\hline $\begin{array}{l}\text { 10. I have delayed an elevator and held the door } \\
\text { open for a stranger. }\end{array}$ & & & & & \\
\hline $\begin{array}{l}\text { 11. I have allowed someone to go ahead of me } \\
\text { in a lineup (at Xerox machine, in the supermarket). }\end{array}$ & & & & & \\
\hline 12. I have given a stranger a lift in my car. & & & & & \\
\hline $\begin{array}{l}\text { 13. I have pointed out a clerk's error (in a bank, at the } \\
\text { supermarket) in undercharging me for an item. }\end{array}$ & & & & & \\
\hline $\begin{array}{l}\text { 14. I have let a neighbour whom I didn't know too } \\
\text { well borrow an item of some value to me } \\
\text { (e.g., a dish, tools, etc.). }\end{array}$ & & & & & \\
\hline $\begin{array}{l}\text { 15. I have bought 'charity' Christmas cards } \\
\text { deliberately because I knew it was a good cause. }\end{array}$ & & & & & \\
\hline $\begin{array}{l}\text { 16. I have helped a classmate who I did } \\
\text { not know that well with a homework } \\
\text { assignment when my knowledge was greater } \\
\text { than his or hers. }\end{array}$ & & & & & \\
\hline $\begin{array}{l}\text { 17. I have before being asked, voluntarily looked after } \\
\text { a neighbour's pets or children without being } \\
\text { paid for it. }\end{array}$ & & & & & \\
\hline $\begin{array}{l}\text { 18. I have offered to help a handicapped } \\
\text { or elderly stranger across a street. }\end{array}$ & & & & & \\
\hline $\begin{array}{l}\text { 19. I have offered my seat on a bus or } \\
\text { train to a stranger who was standing. }\end{array}$ & & & & & \\
\hline 20. I have helped an aquaintance to move househol & & & & & \\
\hline
\end{tabular}

each rater, adding these totals, and then dividing by the number of raters (peer-ratedSRA-scale altruism). A peer rating score was also calculated on the four-item global test by summing across the four items for each rater, adding these totals and dividing by the number of raters (peer-rated-global-altruism).

The reliability of the peer ratings were assessed; split-half reliabilities were computed using odd and even numbered raters across the 80 subjects who had two or more raters. This yielded a significant interrater reliability of $r(78)=+0.51(P<0.01)$ for the peerrated-SRA-scale altruism scores and $r(78)=+0.39(P<0.01)$ for the peer-rated-global- 
Table 2. Means, standard deviations and reliabilities for five samples of SRA-scale respondents

\begin{tabular}{lccccc}
\hline & Sample 1 & Sample 2 & Sample 3 & Sample 4 & Sample 5 \\
\hline Sample size & 99 & 56 & 118 & 146 & 192 \\
Combined mean & 52.01 & 55.34 & 57.09 & 57.11 & 55.47 \\
Standard deviation & 10.12 & 10.46 & 8.89 & 11.70 & 11.70 \\
Coefficient alpha & 0.84 & 0.83 & 0.78 & 0.87 & 0.86 \\
No. of males & 36 & 27 & 39 & 64 & - \\
Mean for males & 52.30 & 55.15 & 55 & 56.29 & - \\
Standard deviation & 10.80 & 9.80 & 7.40 & 12.50 & - \\
No. of females & 63 & 29 & 79 & 82 & - \\
Mean for females & 51.8 & 54.76 & 57.22 & 57.75 & - \\
Standard deviation & 9.8 & 12.50 & 10.00 & 11.00 & - \\
\hline
\end{tabular}

altruism measure. These figures suggest there is some degree of consensus among peers in these ratings of their friends. The internal consistency of the 20 -item peer rating form was also calculated and found to be extremely high $(\alpha=0.89, N=416)$. Other analyses showed reliability in ratings even at the item level (Fekken, 1980). The correlation between peer-rated-SRA-scale altruism and peer-rated-global altruism was $r(86)=0.54$ $(P<0.001)$.

The validity of the SRA-scale was assessed by correlating it with the peer ratings. The correlations between the SRA-scale and peer-rated-SRA-scale altruism and peer-ratedglobal-altruism were $r(86)=0.35(P<0.001)$ and $r(86)=0.21(P<0.05)$, respectively. These correlations were recomputed correcting for attenuation due to unreliability of measurement. Using Spearman's correction formula and substituting coefficient alpha as the reliability of the SRA-scale, and the interrater correlations as the reliabilities of the peer ratings, the correlations of the SRA-scale with peer-rated SRA-scale altruism and peer-rated-global-altruism were raised to $r(78)=0.56$ and $r(78)=0.33$ respectively.

To summarize, the findings from Study 1 support the idea of consistent individual differences in altruistic behavior in two ways. First, there was some agreement among peers' ratings of an individual's altruistic behavior. Second, better than chance agreement was also found between an individual's own report of his or her altruistic behavior and his or her peers' reports.

\section{Study 2: predicting altruistic responses}

The purpose of this study was to provide further evidence for the consistency of altruism by demonstrating that the SRA-scale would be related to other measures of altruism. In this study, carried out with 146 undergraduates over three testing sessions, the SRA-scale was correlated with eight 'altruistic' responses. These included (i) volunteering to read to blind persons in response to a telephone solicitation; (ii) volunteering to participate in experiments for a needy experimenter; (iii) whether they had ever taken a first aid course; (iv) whether they had completed the medical organ donor card which is attached to all Ontario drivers' licenses; (v) a questionnaire measuring 'sensitive attitudes' compiled by the Educational Testing Service (ETS: Derman et al., 1978); (vi) the nurturance scale of the Personality Research Form, an omnibus personality inventory (PRF: Jackson, 1974); (vii) paper-and-pencil measures of helping in emergency 'scenarios;' and (viii) having helping interests on the Jackson Vocational Interest Survey (JVIS: Jackson, 1977).

The means and standard deviations of the self-report altruism scale for this fourth sample are shown in Table 2. The intercorrelations among the SRA-scale and the eight measures described above, as well as with a measure of social desirability responding, are shown in Table 3 above the diagonal. The correlations with social desirability partialled out are shown below the diagonal. The SRA-scale was found to be positively and significantly related to four measures: having filled out the organ donation card, the ETS paper and pencil measure of 'sensitive attitude,' the PRF nurturance scale, and the responses to the altruism simulations. The SRA-scale was also found to predict a linear combination 
of the eight measures at $r=+0.40(P<0.01)$. When corrections were made for the unreliability of the measures, the multiple correlation rose to $r=+0.59$. As can also be seen in Table 3, these results are not due to social desirability response bias.

To summarize, this study also found support for the view that individual differences in altruistic behavior show consistency. It found that an individual's self-reported altruism was related to a variety of altruistic criteria, and that when these criteria were combined, a somewhat stronger relationship obtained.

\section{Study 3: convergent validity}

In order to examine the relationship between the SRA-scale and existing measures of social responsibility, empathy, moral judgment and prosocial values, a variety of scales were given to some 200 university students. These scales included: the Social Responsibility Scale (Berkowitz and Daniels, 1964); the Emotional Empathy Scale (Mehrabian and Epstein, 1972); the Social Interest Scale (Crandall, 1975); the Fantasy-Empathy Scale (Stotland et al., 1978); the Machiavellianism scale (Christie and Geis, 1968); the Rokeach Value Survey (Form C, Rokeach, 1973); the Nurturance scale of the Personality Research Form (PRF: Jackson, 1974); and the Defining Issues Test (Rest, 1979). Although space does not allow a full description of each of these scales, their flavor can be gauged from the following items. "I am the kind of person people can count on," for example, is taken from the Social Responsibility Questionnaire. Items such as the positively loaded "I really get involved with the feelings of the character in a novel" and the negatively loaded "I find it silly for people to cry out of happiness" are from the Empathy Scales. Finally, a measure of social irresponsibility, the Machiavellianism scale, involves agreement with items such as "Anyone who completely trusts anyone else is asking for trouble" and disagreement with "Most men are brave." The social desirability scale of the Personality Research Form (PRF: Jackson, 1974) was also administered.

The means and standard deviations of the self-report altruism scale for this fifth sample are shown in Table 2. The intercorrelations of the various personality tests can be seen in Table 4. The SRA-scale correlated positively with measures of social responsibility, empathy, nurturance, having equality and helpfulness as personal values, having 'high' levels of moral reasoning, and negatively with Machiavellianism. Thus knowledge of how people endorse items such as "I am the kind of person that people can count on" and "I really get involved with the feelings of the character in a novel" allows a greater than chance prediction of whether they report having engaged in such diverse behaviors as making change for a stranger and allowing someone to go first on a xerox machine or at a supermarket check-out counter. The self report altruism scale also predicted an aggregated composite of the nine other measures of prosocial value at $r(135)=+0.44(P<0.001)$.

For a subsample of 93 of the original 200, PRF social desirability scores were avail able. Low but significantly positive relationships were found between social desirability and all the questionnaire measures of prosocial orientation. Nonetheless, when social desirability was covaried, the relationships in Table 4, and that between the SRA-scale and the composite, remained intact.

To summarize, this study found significant positive relations among a variety of questionnaire measures of prosocial orientation. Self-reported altruism was related to all of these, and particularly so to an aggregated composite.

\section{DISCUSSION}

This paper has provided evidence, from both a review of the literature, and from a series of studies using a self-report altruism scale, that there is a broad-based trait of altruism. Knowing a person's score on one item of behavior, or on self-report questionnaires, allows better than chance prediction of that person's behavior in other test situations. The Self-Report Altruism Scale, for example, correlated significantly positively with peer-ratings of altruism, whether students had completed the medical organ-donor card which is attached to all Ontario drivers' licences, and a variety of paper-and-pencil- 


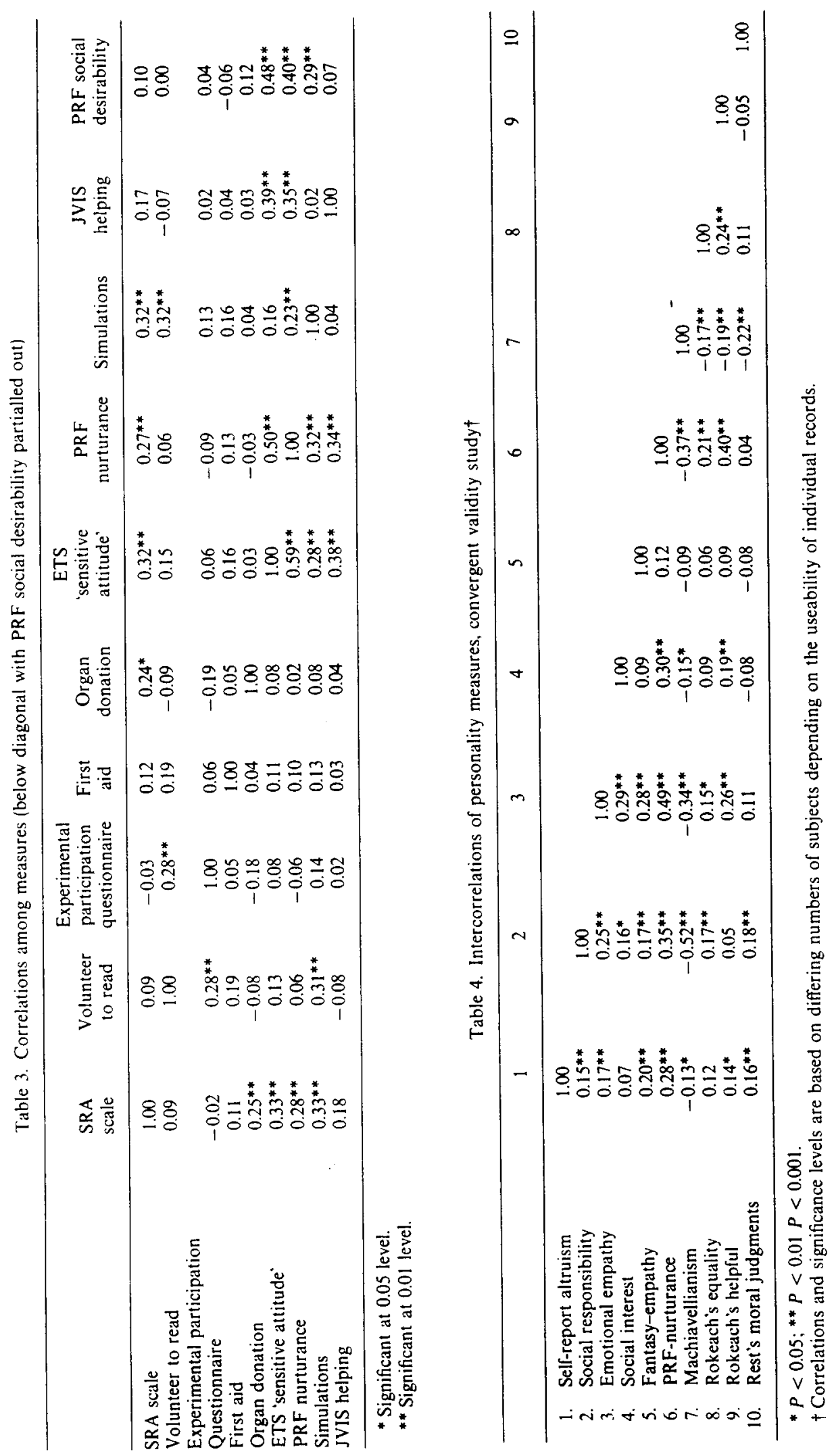


measures of moral reasoning, nurturance, sensitive-attitude, social responsibility, empathy and prosocial values. Although all of these correlations are low, taken together they support the idea of a broad based prosocial disposition. People high in prosocial disposition are expected to behave prosocially over a diverse range of situations. Although any two measures intercorrelate, on average, only a modest +0.20 , higher correlations typically occur if the principal of aggregation is adhered to.

It is worth noting that many of the individual questionnaires used in the last study (Table 4) have been found to predict situational tests of altruistic behavior. This literature has been reviewed by Rushton (1980), but a few of the studies might briefly be described. Berkowitz and Daniels (1964) found the Social Responsibility Scale to predict the number of items made for a person allegedly dependent on the subject. Midlarsky and Bryan (1972) used a similar scale with children and found it to predict donating to charity on both immediate and subsequent tests. Mehrabian and Epstein (1972) found that people's empathy scores predicted both a refusal to administer high levels of electric shock, and agreement to help an emotionally upset person. Staub (1974) found that a number of questionnaire measures including social responsibility, Machiavellianism, moral judgment, and having helpful values, grouped together on a single factor in a factor analysis, along with high scores on actual helping.

One aspect of Staub's (1974) study was that a person's level of moral judgment, measured using Kohlberg's (1969) dilemmas, correlated with traditional moral attitudes, as well as with helping behavior. An interesting aspect of Table 4 in this regard is the positive relation between Rest's (1979) Defining Issues Test of moral judgment and the traditional questionnaires of social responsibility, as well as with self-report altruism. It would seem that the relationship between high moral judgment and altruistic behavior is a positive one, as other studies, also reviewed by Rushton (1980), demonstrate.

In short, there appears to be a trait of altruism. This trait can be assessed by the manner in which a person endorses or responds to items on a number of pencil-andpaper-measures of moral judgment, social responsibility, and moral knowledge, all of which, in turn, are related to more overt behavior.

In regard to the Self-Report Altruism Scale, while it has been useful for demonstrating the broad-base of the prosocial behavior trait, it is probably not a maximally effective way of measuring this trait. It may be too specific. The more usual format of personality inventories is to ask a respondent to make general inferences about himself or herself. By requiring our respondents to make highly specific statements as to their past behavior (e.g. "I have donated blood-never, once, more than once, often, and very often") we constrained their answers. This was a quite deliberate policy for we wished to measure something quite behaviorally concrete. And we have demonstrated that such concrete and specific behavioral items are predictive of each other, as well as of more global measures. Furthermore the items are remarkably free of such response biases as social desirability. However, to tap maximally into the broad based trait of prosocialness, it might be more useful to employ a more general and global response format than the one used here. One alternative is to ask respondents to imagine they are in a situation where they could engage in the sort of items on the SRA-scale, and then to estimate the probability that they would do so. Alternatively researchers may prefer to employ a combination of the nurturance, social responsibility, and empathy scales described above.

Having qualified our enthusiasm for our research instrument, we should nonetheless point out that there is evidence that the scale does relate to certain expected antecedents of altruistic behavior. In unpublished pilot data we found SRA-scale scores related to such self-report socialization antecedents as whether the respondent had an altruistic parent. There is a large literature to suggest that parental models are of great importance in the early development of altruistic behavior (Rushton, 1980). An adequate research instrument in this area would also allow us to test the interesting ideas, emerging out of sociobiology, that heredity may make a contribution to the consistent patterns of individual differences in human altruism (Eysenck, 1980; Rushton, 1980; Wilson, 1975). These are exciting research possibilities for the future. 
Acknowledgements--Research support was provided by Grant No. 410-78-1061 from the Social Sciences and Humanities Research Council of Canada, J. Philippe Rushton principal investigator. Studies 1 and 2 are based on a 1980 dissertation submitted by G. Cynthia Fekken to The University of Western Ontario in partial fulfillment of the requirements for the M.A. degree.

We would like to thank Natalie Allen and Ron Holden for their help in gathering the data, Douglas $\mathbf{N}$. Jackson for constructive criticism and interest and Steve Lupker for suggestions regarding the SRA-scale.

\section{REFERENCES}

Berkowitz L. and Daniels L. R. (1964) Affecting the salience of the social responsibility norm: effects of past help on the response to dependency relationships. J. abnorm. soc. Psychol. 68, 275-281.

Burton R. V. (1963) Generality of honesty reconsidered. Psychol. Rev. 70, 481-499.

ChrIstre R. and GeIs G. (Eds) (1968) Studies in Machiavellianism. Academic Press, New York.

Crandall J. E. (1975) A scale for social interest. J. individ. Psychol. 31, 187-195.

Derman D., French J. W. and Harman H. H. (1978) Guide to Factor Referenced Temperament Scales 1978. Educational Testing Service, Princeton.

DLUGOKINSKI E. and FIRESTONE I. J. (1973) Congruence among four methods of measuring other-centeredness. Child Dev. 44, 304-308.

DLugokinski E. and Firestone I. J. (1974) Other centeredness and susceptibility to charitable appeals: effects of perceived discipline. Devl Psychol. 10, 21-28.

Eysenck H. J. (1939) The validity of judgments as a function of the number of judges. J. exp. Psychol. 25, $650-654$.

EYSENCK H. J. (1977) Crime and Personality, 3rd edn. Granada Publishing Ltd, St Albans, England.

EYSENCK H. J. (1980) Behavior Modification, Behavior Therapy and Other Matters: A Dialogue with B. $F$. Skinner. Paper presented at the 88th Annual Convention of the American Psychological Association, Montreal, Canada, September, 1980.

FEKKEN G. C. (1980) The Validation of a Self-Report Measure of Altruism. Unpublished Masters Thesis: The University of Western Ontario.

HARTSHORNE H. and MAY M. A. (1928) Studies in the Nature of Character, Vol. I, Studies in Deceit. Macmillan, New York.

HARTShorNe H., MAY M. A. and MAller J. B. (1929) Studies in the Nature of Character, Vol. II, Studies in Self-Control. Macmillan, New York.

HARTSHORNe H., MAY M. A. and ShUtrleworth F. K. (1930) Studies in the Nature of Character, Vol. III, Studies in the Organization of Character. Macmillan, New York.

JACKson D. N. (1974) Personality Research Form Manual, Revised edn. Research Psychologists Press, Port Huron, Michigan.

Jackson D. N. (1977) Jackson Vocational Interest Survey Manual. Research Psychologists Press, London.

KOHLBERG L. (1969) Stage and sequence: the cognitive-developmental approach to socialization. In Handbook of Socialization Theory and Research (Edited by GosuIN D.). Rand-McNally, Chicago.

KreBS D. L. (1978) A cognitive-developmental approach to altruism. In Altruism, Sympathy and Helping Psychological and Sociological Principles (Edited by WISPÉ L.). Academic Press.

KREBS D. L. and SturRUP B. (1974) Role-taking ability and altruistic behavior in elementary school children Person. soc. Psychol. Bull. 1, 407-409.

LATANÉ B. and Darley J. M. (1970) The Unresponsive Bystander: Why doesn't he Help? Appleton-CenturyCrofts, New York.

MALLER J. B. (1934) General and specific factors in character. J. soc. Psychol. 5, 97-102.

Mehrabian A. and Epstein N. (1972) A measure of emotional empathy. J. Person. 40, 525-543.

MidlarsKy E. and Bryan J. H. (1972) Affect expressions and children's imitative altruism. J. exp. Res. Person. 6, 195-203.

Mischel W. (1968) Personality and Assessment. Wiley, New York.

Rest J. R. (1979) Development in Judging Moral Issues. Univ. of Minnesota Press, Minneapolis, Minnesota.

RoKeach M. (1973) The Nature of Human Values. Free Press, New York.

Rushton J. P. (1976) Socialization and the altruistic behavior of children. Psychol. Bull. 83, 898-913.

Rushtron J. P. (1980) Altruism, Socialization and Society. Prentice-Hall, Englewood Cliffs, New Jersey.

Rushron J. P. and CHRissohn R. D. (1981) Extraversion, neuroticism, psychoticism and self-reported delinquency: evidence from eight separate samples. Person. individ. Diff. 2, 11-20.

Rushton J. P. and Sorrentino R. M. (Eds) (1981) Altruism and Helping Behavior. Lawrence Erlbaum Associates, Hillsdale, New Jersey.

Rushton J. P. and Wheflwright M. (1980) Validation of donating to charity as a measure of children's altruism. Psychol. Rep. 47, 803-806.

RUTHERFORD E. and MUSSEN P. (1968) Generosity in nursery school boys. Child Dev. 39, 755-765.

Spearman C. (1910) Correlation calculated from faulty data. Br. J. Psychol. 3, 271-295.

STAUB E. (1974) Helping a distressed person: social, personality and stimulus determinants. In Advances in Experimental Social Psychology, Vol. 7 (Edited by Berkowitz L.). Academic Press, New York.

Stotland E., Mathews K. E., Sherman S. E., Hansson R. O. and Richardson B. Z. (1978) Empathy, Fantasy and Helping. Sage, Beverly Hills, California.

STRAYER F. F., WAREING S. and RUSHTON J. P. (1979) Social constraints on naturally occurring preschool altruism. Ethology Sociobiol. 1, 3-11.

WILSON E. O. (1975) Sociobiology: The New Synthesis. Harvard Univ. Press, Cambridge, U.S.A. 